\title{
Políticas educacionais e o ensino de Ciências no Brasil: o caso do IDEB
}

\section{Educational policies and Science education in Brazil: IDEB case}

\author{
Paulo Sergio GARCIA \\ Leandro PREARO ${ }^{2}$ \\ Maria Carmo ROMEIRO ${ }^{3}$ \\ Marcus BASSI ${ }^{4}$
}

\begin{abstract}
Resumo
O Índice de Desenvolvimento da Educação Básica (IDEB) monitora a qualidade do Ensino Fundamental, focando as disciplinas de Português e Matemática (PM). Esse foco exclusivo nessas disciplinas leva os estudantes a valorizá-las em detrimento de Ciências. Neste estudo investigou-se a percepção dos jovens, na região do grande $\mathrm{ABC}$ (São Paulo), quanto à importância das disciplinas estudadas cotidianamente. Os resultados mostraram que os alunos atribuem grande relevância às disciplinas de PM, induzidos pelas açóes dos professores, da escola e das redes de ensino, que buscam melhores posiçóes no ranking do IDEB. Esses dados sáo importantes para promover discussóes entre escolas e secretarias de educação sobre políticas educacionais brasileiras.
\end{abstract}

Palavras-chave: Educação Básica. Políticas Públicas. Ensino de Ciências.
Abstract

The Basic Education Development Index has been monitoring the Fundamental Education, focusing on the subjects of Portuguese and Mathematics (PM). This exclusive focus on PM has taken students to overvalue them in detriment of Science. In this study, it was investigated students' perception on the relevance of school subjects studied at daily-basis. Results showed that the students attributed great importance to the PM disciplines, induced by their teachers, school and department of education' actions, who seek better positions on the IDEB ranking. These data are important to promote discussions between schools and education departments on Brazilian educational policies.

Keywords: Basic Education. Public Policies. Science Teaching.

1 Pós Doutor em educação, coordenador do Observatório de Educação do Grande ABC, professor dos cursos de graduação e pós-graduação da Universidade Municipal de São Caetano do Sul. São Caetano do Sul/ SP - Brasil. CEP: 09550-051. Tel.: 4239-3200. Email: <paulo.garcia@uscs.edu.br>.

2 Professor Doutor, pesquisador do Observatório de Educaçáo do Grande ABC, professor dos cursos de graduação e pós-graduação da Universidade Municipal de São Caetano do Sul. São Caetano do Sul/ SP Brasil. CEP: 09550-051. Tel.: 4239-3200. Email: <leandro.prearo@uscs.edu.br>.

3 Professora Doutora, pesquisadora do Observatório de Educação do Grande ABC, professora dos cursos de graduação e pós-graduação da Universidade Municipal de São Caetano do Sul. São Caetano do Sul/ SP - Brasil. CEP: 09550-051. Tel.: 4239-3200. Email: <mcromero@uscs.edu.br>.

4 Professor Doutor, pesquisador do Observatório de Educaçáo do Grande ABC, professor dos cursos de graduação e pós-graduação da Universidade Municipal de São Caetano do Sul. São Caetano do Sul/ SP Brasil. CEP: 09550-051. Tel.: 4239-3200. Email: <mbassi@uscs.edu.br>.

\begin{tabular}{|l|l|l|l|l|l|} 
R. Educ. Públ. & Cuiabá & v. 27 & n. 64 & p. 251-274 & jan./abr. 2018 \\
\hline
\end{tabular}




\section{Introdução}

No Brasil, nas últimas décadas, a Educação Básica, o Ensino Fundamental e o Ensino Médio, vêm sendo monitorados por meio de índices que avaliam o desempenho dos alunos em testes padronizados, utilizando também as taxas de aprovação e reprovação da escola. Os estados também criaram mecanismos para avaliar o rendimento dos jovens. No estado de São Paulo, por exemplo, o Índice de Desenvolvimento da Educação do Estado de São Paulo (IDESP) foi criado pelas autoridades educacionais locais com o objetivo de monitorar a educação. O IDESP é um indicador de qualidade do Ensino Fundamental e do Médio que utiliza o desempenho dos alunos nos exames do Sistema de Avaliaçáo de Rendimento Escolar do Estado de São Paulo (SARESP) e o fluxo escolar.

Em nível nacional, o Índice de Desenvolvimento da Educação Básica (IDEB), criado pelo Decreto no 6.094 , de 24 de abril de 2007 (BRASIL, 2007), foi implantado para acompanhar e monitorar a qualidade das escolas de Ensino Fundamental e Médio. Tal índice combina o desempenho dos alunos e o fluxo escolar.

A criação do IDEB representa uma iniciativa precursora no Brasil, pois a partir dele é possível acompanhar a qualidade do ensino sob dois aspectos igualmente importantes: o rendimento escolar, traduzido pelas taxas de aprovação, reprovaçáo e abandono, e o desempenho, captado por meio das médias na Prova Brasil. A lógica desse indicador relaciona-se à ideia de que em uma escola de qualidade o aluno avança em seu percurso formativo, passa de ano e aprende, sem desperdiçar tempo com reprovações.

Trata-se de um indicador que tem como premissa a ideia de que um sistema educacional em que os estudantes fracassam sistematicamente e que uma grande parte abandona a escola antes de completar a Educação Básica não é um sistema desejável, mesmo que uma parcela dos jovens finalize a Educação Básica, atingindo altos desempenhos nos exames padronizados. Também não é desejável que todos os estudantes concluam o Ensino Fundamental, no período correto, mas com pouco aprendizado.

A criação do IDEB trouxe implicaçôes positivas, pois ele auxilia os especialistas e gestores na análise da educação brasileira. A partir dele, o Ministério da Educação (MEC) pode lançar novas políticas para enfrentar o problema do fracasso escolar e o índice pode ainda auxiliar na mobilização da sociedade brasileira, uma vez que ele existe em âmbito nacional e está à disposição do público em geral por meio das mídias sociais.

No entanto, tal indicador também trouxe efeitos negativos, uma vez que rankings escolares são criados e publicados pela imprensa, promovendo a competição entre as escolas públicas (ASSIS; AMARAL, 2013). Há, também, a 
questão de que um índice baseado, exclusivamente, em Português e Matemática não é capaz de captar a complexidade da escola e nem sua qualidade. Além disso, alguns sistemas e redes de ensino têm utilizado testes de preparação em Português e Matemática, nos quintos e nonos anos, com o objetivo de preparar os alunos especificamente para a Prova Brasil (RONCA, 2013) e, em muitos casos, os professores dessas disciplinas têm sido responsabilizados pelo bom ou mau desempenho dos jovens e das escolas.

Quanto a essa preparação, Coutinho (2012) mostrou que na cidade de Duque de Caxias havia várias açóes que se destinavam a esse objetivo, preparar os alunos para os exames. Entre elas um projeto que contava com estagiários para trabalharem os conteúdos específicos da Prova Brasil com os alunos do $4^{\circ}$ Ano da rede, um programa de reforço escolar e iniciativas de simulados, todos eles focados nas disciplinas de Português e Matemática.

Fazio e Karrow (2014) mostraram que essa ênfase exclusiva na leitura e no cálculo afetou negativamente a qualidade do ensino de Ciências na província de Ontário no Canadá. As iniciativas organizadas, focando a leitura e o cálculo, incluindo políticas de responsabilizaçáo dos professores e testes em larga escala, acabaram, por consequência, negligenciando o ensino de Ciências no Ensino Fundamental. Tal fato foi observado, pelos pesquisadores, em entrevistas com os professores, observações informais nas escolas e análises sobre os recentes resultados da avaliação científica do Trends in International Mathematics and Science Study (TIMSS).

Também nos Estados Unidos, Baker et al. (2010, p. 4, tradução nossa) mostraram que a ênfase exclusiva em matemática básica e leitura

[...] pode levar ao estreitamento e reduzir o currículo apenas aos temas que são testados, tirando a atenção da história da ciência, das artes, cidadania e língua estrangeira, bem como da escrita, da investigaçáo, e de tarefas mais complexas de solução de problemas.

No Brasil, especificamente na regiáo do grande $A B C$ Paulista, suspeita-se que esse excesso de ênfase nas disciplinas de Português e Matemática, decorrente da busca pela obtenção de melhores posiçóes no ranking do IDEB, cria ou reforça um imaginário na mente dos alunos e da comunidade de que essas disciplinas são as mais importantes no cotidiano escolar, sobrepondo-se às outras disciplinas, em geral, e ao ensino de Ciências, em particular. Este estudo de caso procura testar essa hipótese, realizando uma avaliação sobre a percepção dos alunos em relação à importância das disciplinas estudadas cotidianamente na escola com a presença do IDEB. Pretende-se compreender se existe essa valorização e como ela foi constituída. 


\section{As Lógicas do IDEB}

O Decreto no 6.094, de 24 de abril de 2007, mostra que:

Art.3o A qualidade da educação básica será aferida, objetivamente, com base no IDEB, calculado e divulgado periodicamente pelo INEP, a partir dos dados sobre rendimento escolar, combinados com o desempenho dos alunos, constantes do censo escolar e do Sistema de Avaliação da Educação Básica - SAEB, composto pela Avaliação Nacional da Educação Básica - ANEB e a Avaliação Nacional do Rendimento Escolar. (BRASIL, 2007).

O IDEB procura ampliar as possibilidades de mobilização da sociedade em prol da educação, pois o indicador permite a comparação nacional por meio dos resultados que reúnem aprendizagem e fluxo. $\mathrm{O}$ equilíbrio dessas duas dimensôes prevê que se uma rede ou sistema de ensino contar com muitas retençóes para obter resultados de melhor qualidade na Prova Brasil o fluxo será afetado, indicando problemas de qualidade. Por outo lado, se a escola aprova o aluno sem ele demonstrar conhecimento, o resultado da Prova Brasil indicará também a necessidade de melhoria do sistema. Trata-se de uma política pública que busca a qualidade da educação. Uma ferramenta para o acompanhamento das metas de qualidade do Plano de Desenvolvimento da Educação, que estabelece como meta que em 2022 o IDEB do Brasil será de 6,0 (meta média comparável a um sistema educacional de qualidade e dos países desenvolvidos).

O IDEB, considerado mais do que simplesmente um indicador estatístico, é um condutor de políticas para a melhoria da qualidade da educação, em nível nacional, estadual, municipal e das escolas. Ele possibilita a criação de metas individuais intermediárias para as escolas, possibilitando a busca pela qualidade do ensino. Tais metas são os percursos estabelecidos de evolução individual dos índices, para que o Brasil atinja o patamar educacional dos países da Organizaçáo para a Cooperação e Desenvolvimento Econômico (OCDE). Tal situação significa avançar da média nacional de 3,8, em 2005, para um IDEB igual a 6,0, na primeira fase do Ensino Fundamental.

As metas são diferenciadas para cada rede de ensino e escolas e apresentadas bienalmente. A ideia central é que cada estado, município e escola melhorem seus indicadores, contribuindo para que o Brasil chegue a meta 6,0 em 2022, ano do bicentenário da independência. Mesmo para aqueles estabelecimentos de ensino que já atingiram a meta, está prevista a continuação na melhoria e para 
aquelas redes e escolas que apresentaram problemas é previsto apoio específico para reduzir essa desigualdade.

O indicador apresenta, como cita Ronca (2013), alguns pontos positivos, como a articulaçáo entre os conceitos de fluxo e de desempenho, favorecendo o entendimento parcial da qualidade das escolas e dos sistemas e auxiliando os gestores e os professores na identificaçáo de competências e dificuldades dos alunos nas disciplinas avaliadas, qual seja Português e Matemática. O IDEB auxilia também no diagnóstico, no monitoramento e no agrupamento de informações para a criação de políticas públicas, estabelecendo metas objetivas e individualizadas para cada escola, sistema de ensino, municípios e estados brasileiros. Tal situação tem o objetivo, entre outros, de controlar e elaborar açóes para combater o fracasso escolar.

No entanto, o índice também apresenta várias limitaçôes. De fato, não é possível assumir o IDEB como dispositivo de compreensão da qualidade da Educaçáo Básica. É difícil comparar escolas, por exemplo, com condiçóes de infraestrutura diferentes (GARCIA et al., 2014). As avaliações em larga escala, utilizando somente dois fatores, quais sejam, o fluxo escolar e o desempenho dos alunos, associados diretamente com a questão da leitura e da Matemática, não são capazes de captar a complexidade da escola.

De acordo com Garcia (2015), a complexidade da escola não pode ser captada por um único indicador de qualidade. Muitas outras dimensôes estáo relacionadas. $\mathrm{O}$ autor afirma que não há um fator isolado que explique o bom desempenho dos alunos. Existem múltiplos fatores que sustentam e apoiam a sua aprendizagem e o seu bom desempenho. $\mathrm{Na}$ escola existe uma grande variedade de mecanismos que atuam de forma combinada e que são mais intensos do que qualquer fator individual agindo isoladamente (RUTTER, 1979). Esses pesquisadores sugeriram que há um tipo de ethos global da escola. Nesse sentido, Barbosa e Fernandes (2001) afirmam que são diversos os fatores que atuam, concomitantemente, em vários níveis da inserção social para determinar a boa performance dos estudantes e que esse rendimento é o resultado dessa complexa interação.

Garcia et al. (2014) afirmam também que a comparação entre as escolas fica depreciada pelo fato de algumas estarem localizadas em áreas de risco, sem infraestrutura adequada, com professores mal formados e condiçóes de trabalho precárias, atendendo jovens oriundos de famílias pobres, de baixa renda, com pais, muitas vezes, analfabetos, ou sem a presença deles, e outras situadas nos grandes centros, com boa infraestrutura, professores com formação adequada, estudantes de famílias com alto Nível Socioeconômico (NSE) e com elevado capital cultural.

O IDEB também não fornece informaçóes no sentido de compreender se a escola é eficaz e justa. As escolas eficazes, como afirma Mortimore (1991), 
são aquelas que auxiliam seus alunos a obter desempenho educacional além do esperado, considerando a origem social dos jovens e a composiçáo social do corpo discente da escola. Portanto, esse indicador náo associa a ideia de qualidade e equidade. Nesse sentido, é possível que uma escola tenha alto desempenho (notas de Português e Matemática altas) e, ao mesmo tempo, apresente um fluxo escolar baixo, indicando que se trata de uma escola eficaz, porém náo justa, pois muitos alunos ficaram para traz, fracassaram e, muitas vezes, foram excluídos da instituição. Assim, a escola pode ter um IDEB alto e ter desigualdade, sendo discriminatória.

Como afirma Ronca (2013), pode acontecer de apresentar

[...] um alto IDEB e desigualdade. Os gestores não dispóem de informaçóes, a partir do IDEB, sobre as razôes do resultado obtido por determinada escola e sobre o desempenho de alunos pobres, negros, pardos ou índios. Podemos chegar, então, ao paradoxo de uma escola com bom desempenho no IDEB praticar a discriminação ou não ter estratégias para lidar com a desigualdade. A relação entre indicadores da qualidade da educação e equidade é de fundamental importância no contexto atual da sociedade brasileira, profundamente marcada pela desigualdade. Trata-se de uma característica que envolve questôes de raça, gênero, nível socioeconômico e que se configura, também, em relação às regiôes geográficas em que o país é dividido. (RONCA, 2013, p. 80-81).

Outra questão importante relaciona-se ao fato de que o IDEB é construído com a média dos resultados dos alunos que realizam a prova. Nesse contexto, a escola não dispóe de informaçóes específicas sobre, por exemplo, o desvio padráo para conhecer a variaçáo dos dados, sendo que, dessa maneira, um grupo de bons alunos pode influenciar a média. Assim, não é descabido supor que escolas, na tentativa de obter um IDEB mais alto, impedem aqueles estudantes considerados mais fracos no aprendizado de realizar o exame. Tal processo tem acontecido porque o indicador tem se transformado em um ranking de escolas e sistemas, acompanhado pela mídia, interpretado de forma isolada e não contextualizada (ASSIS; AMARAL, 2013).

Outra consequência que pode ser destacada é que os professores, sobretudo, os das disciplinas de Português e Matemática, têm sido responsabilizados pelo sucesso ou fracasso dos alunos, resultado de um processo que náo considera a complexidade da escola. Tal situação, entre outras coisas, tem gerado também 
a implantação dos mecanismos de meritocracia, marcados pela ação de bônus como prêmios para a melhoria da escola (sucesso do professor), da rede ou sistema de ensino.

Em um mundo marcado pela competitividade entre os países, a educaçáo passou a ser vista como sinônimo de produtividade, e a formação para a cidadania cedeu espaço a uma preparação mais voltada para o trabalho. Esse fator competitivo, que é essência da meritocracia, é também um dos fatores que vem causando estresse no sistema educacional na Educação Básica. Diretores e professores têm sido mais cobrados e responsabilizados pelo sucesso ou fracasso dos alunos. Aqueles, sobretudo que lecionam as disciplinas de Português e Matemática, sentem-se pressionados pelos gestores escolares e pelos colegas para a obtenção de resultados e, muitas vezes, transferem tal pressão para os alunos, instituindo nas aulas testes similares àqueles que acontecem na Prova Brasil. Nesse contexto, Madaus, Russell e Higgns (2009) sinalizam que estudantes e professores quando pressionados pela busca de bons resultados nessas avaliações externas podem sofrer problemas de saúde (stress), perderem a motivação ou criarem um sentimento negativo em relação à escola.

No entanto, é preciso considerar que a meritocracia oculta desigualdades nos sistemas de educação, sobretudo do ponto de vista da garantia da infraestrutura das escolas e do custo-aluno-qualidade. A avaliação por mérito na educação responsabiliza os professores, mas não considera e nem distingue as condiçóes em que eles concorrem para a obtençáo do reconhecimento meritocrático. Em condiçóes desiguais, o mérito torna-se plausível para alguns e inatingível para outros. Tal situação tem gerado certo preconceito e puniçóes entre os que náo alcançam os objetivos.

Em seu artigo, Responsabilização, meritocracia e privatização: conseguiremos escapar ao neotecnicismo?, Freitas (2011) realiza uma análise profunda sobre a mercantilização da educação, mostrando que a responsabilização acontece a partir da incorporação de tecnologias para ampliar o controle sobre diretores, professores e alunos por meio da avaliaçáo de padróes de internacionais de desempenho e de pagamento por meritocracia combinadas com a privatizaçáo de escolas. Sistema, segundo o autor, amplamente usado nos Estados Unidos, que torna a educação um subsistema do aparato produtivo, cujos objetivos são definidos, internacionalmente, pela $\mathrm{OCDE}$ via Programa Internacional de Avaliação de Alunos (PISA).

Apesar dessas discussóes e das limitaçóes, o IDEB é um indicador que auxilia na monitorização da Educação Básica e se torna relevante para que os especialistas e gestores escolares reflitam sobre as escolas e o desempenho dos alunos, afastado, evidentemente, das premissas de criação de rankings de escolas, dos processos de 
responsabilização e de meritocracia associados aos professores, e aliado a outras formas de avaliação da escola. Além disso, o IDEB possibilita que os pais e a comunidade em geral participem mais do debate sobre a educação no país e, ao mesmo tempo, pressionem os governos locais e central para, efetivamente, melhorar a qualidade do ensino.

\section{O ensino de Ciências no contexto da Educação Básica}

O ensino de Ciências, em uma sociedade que convive com uma alta valorização do conhecimento científico e com amplo crescimento da tecnologia, corrobora com a formação de um cidadão crítico, sinalizado pelas diretrizes da Educação Básica e do Ensino Fundamental. Trata-se de um espaço privilegiado para a reflexão sobre as diferentes explicações sobre o mundo, sobre os fenômenos da natureza e a ação do homem nesse contexto. Em tal espaço, os alunos podem contrapor e avaliar tais explicaçóes, o que permite o desenvolvimento de uma postura reflexiva, crítica, questionadora e investigativa. Os alunos aprendem sobre fatos, definiçóes, conceitos, teorias e leis e, também, sobre o método científico, que se relaciona com a observação, medição, estimativa, inferência, classificação, conclusão, enfim, a criatividade (BRASIL, 1997).

O ensino de Ciências favorece também a compreensão de conceitos e procedimentos que possibilitam o questionamento dos fenômenos da natureza e o entendimento sobre as questôes éticas implícitas nas relaçôes entre Ciência, Tecnologia e Sociedade. Além disso, sua abrangência inclui a compreensão da crise ambiental, abrangendo a destruição dos seres humanos. Trata também de questóes atuais e polêmicas como o consumismo, a manipulação gênica, o destino dado ao lixo industrial, hospitalar e doméstico, assuntos que estáo inseridos no contexto dos alunos.

Em muitos países (Canadá, Austrália) a Ciência, e em graus diferentes a tecnologia, são elementos-chave para a escolarização. Em uma sociedade globalizada, os conhecimentos derivados do ensino de Ciências e Tecnologia $(\mathrm{C} \& \mathrm{~T})$ são vistos como relevantes para o desenvolvimento da cidadania e a preparação para o trabalho. Tais questôes inspiraram movimentos importantes, como Ciência para todos e Alfabetização cientifica e tecnológica (TOLENTINO NETO, 2008).

Apesar dessa importância, o ensino de Ciências tem enfrentado vários desafios. Vários esforços têm sido envidados para sua renovação, buscando avanços metodológicos, no entanto, não foram suficientes para mudar as 
bases desse ensino, que continua assentado na transmissão de informaçóes, aulas expositivas e utilização do livro didático. Nessa direção, Bizzo (2009) já havia mostrado que muitas pesquisas apontavam a premissa da memorização como uma das causas do fracasso do ensino de Ciências no Brasil.

Além desse quadro de transmissão de informações e memorização, os estudos do PISA (2009, 2012), mostraram que a disciplina de Ciências é aquela que os estudantes brasileiros estáo mais defasados quando comparados aos outros países. Outro estudo realizado em 45 países, por meio do projeto Relevance of Science Education (ROSE), investigou, com a utilização de questionários aplicados a estudantes na faixa dos 15 anos de idade, o que os jovens brasileiros consideravam importante no aprendizado de Ciência e Tecnologia. A pesquisa mostrou a rejeição dos alunos de Ensino Fundamental e Médio à Ciência.

Tolentino Neto (2008), também, que em muitos países o ensino de Ciências tem enfrentado problemas, como a falta de interesse por parte dos jovens. Tal situação tem feito com que iniciativas sejam lançadas para enfrentar esses desafios, a saber, o projeto Ciência Viva, em Portugal, e Brasil 2006, da Sociedade Brasileira para o Progresso da Ciência (SBPC). De fato, a falta de interesse pelo ensino de Ciências é um dos grandes problemas a ser enfrentado, contudo, o IDEB pode tornar ainda mais complicada a situação, na medida em que o foco da construçáo desse indicador está baseado nas disciplinas de Português e de Matemática.

\section{A Região do Grande ABC Paulista}

A região do Grande $\mathrm{ABC}$ ou $\mathrm{ABC}$ Paulista é parte da regiáo metropolitana da capital do Estado de São Paulo (a Grande São Paulo). Foi reconhecida pelos movimentos sindicalistas e pela alta industrialização. A área é compreendida por sete municípios: Santo André, São Bernardo do Campo, São Caetano do Sul, Diadema, Mauá, Ribeirão Pires e Rio Grande da Serra.

Dados recentes do Instituto Brasileiro de Geografia e Estatística (IBGE) mostram que a região conta com mais de 2,5 milhôes de habitantes, área de $635 \mathrm{~km}^{2}$ (IBGE, 2014) e Produto Interno Bruto (PIB) industrial com aproximadamente $\mathrm{R}$ \$ 27 bilhóes, considerado o segundo do estado e o terceiro do país. O Quadro 1 sintetiza os atributos demográficos da região: 


\section{Quadro1 - Características demográficas da região}

\begin{tabular}{|l|r|r|r|r|r|r|r|}
\hline & S.André & \multicolumn{1}{|c|}{ S. Bernardo } & \multicolumn{1}{c|}{ S. Caetano } & \multicolumn{1}{c|}{ Diadema } & Mauá & Ribeirão Pires & $\begin{array}{c}\text { Rio } \\
\text { Grande }\end{array}$ \\
\hline População & 704.942 & 805,895 & 156.362 & 406.718 & 444.136 & 118.871 & 47.142 \\
\hline $\begin{array}{l}\text { Área territorial } \\
\text { (Km2) }\end{array}$ & 175,781 & 409,478 & 15,33 & 30,796 & 61,866 & 99,119 & 36,341 \\
\hline PIB (milhões) & 17.664 .718 & 36.337 .338 & 11.762 .744 & 11.786 .624 & 7.633 .782 & 1.978 .256 & 529.413 \\
\hline Posição do PIB & $33^{\mathrm{a}}$ & $14^{\mathrm{a}}$ & $48^{\mathrm{a}}$ & $47^{\mathrm{a}}$ & $79^{\mathrm{a}}$ & $287^{\mathrm{a}}$ & $816^{\mathrm{a}}$ \\
\hline IDH-M ${ }^{5}$ 2010 & 0,815 & 0,805 & 0,862 & 0,757 & 0,766 & 0,784 & 0,749 \\
\hline $\begin{array}{l}\text { Renda Familiar } \\
\text { (\$) }\end{array}$ & 1.499 & 1.394 & 2.349 & 917 & 815 & 974 & 747 \\
\hline $\begin{array}{l}\text { Anos de estudo } \\
\text { (Anos) }\end{array}$ & 10 & 10 & 11 & 08 & 09 & 09 & 09 \\
\hline $\begin{array}{l}\text { Acesso à } \\
\text { internet } \\
\text { em casa (\%) }\end{array}$ & 72,7 & 81,7 & 73,4 & 57,2 & 65,2 & 62,6 & 52,6 \\
\hline
\end{tabular}

Fonte: Dados do Observatório de Educação do Grande ABC.

Trata-se de uma regiáo com características bem distintas em termos de área, população e PIB (São Bernardo possui as maiores). São Caetano, nesse contexto, apresenta o maior Índice de Desenvolvimento Humano Municipal e a maior média renda familiar ( $\mathrm{R} \$ 2.349,00)$. A população das cidades tem, em média, dez anos de estudo.

Os Quadros 2 e 3 apresentam o número de escolas e de matrículas no Ensino Fundamental, de acordo com os dados do Censo Escolar de 2015:

Quadro 2 - Número de escolas do grande ABC - 2015

\begin{tabular}{|c|c|c|c|c|c|c|c|c|c|}
\hline \multicolumn{2}{|c|}{ Número de escolas } & \multicolumn{7}{|c|}{ Cidades } & \\
\cline { 2 - 10 } & AS & SBC & SCS & DIA & MAU & RP & RGS & GABC \\
\hline Municipal & E.F. I II & 50 & 77 & 20 & 28 & 16 & 9 & - & 200 \\
\hline Estadual & E.F. I III & 86 & 72 & 10 & 56 & 64 & 29 & 11 & 328 \\
\hline
\end{tabular}

Fonte: Dados do Observatório de Educação do Grande ABC.

5 Índice de Desenvolvimento Humano Municipal. 
Quadro 3 - Número de matrículas do grande ABC - 2015

\begin{tabular}{|c|c|c|c|c|c|c|c|c|c|}
\hline \multicolumn{2}{|c|}{$\begin{array}{c}\text { Número de } \\
\text { matrículas }\end{array}$} & \multicolumn{9}{|c|}{ Cidades } \\
\cline { 2 - 10 } Municipal & $\begin{array}{c}\text { E.F.I } \\
\text { e II }\end{array}$ & 18.070 & 45.488 & 11.211 & 13.094 & 3.030 & 2.476 & - & 80.275 \\
\hline Estadual & $\begin{array}{c}\text { E.F.I } \\
\text { e II }\end{array}$ & 43.769 & 60.558 & 2.080 & 34.967 & 40.270 & 9.054 & 4.624 & 195.322 \\
\hline
\end{tabular}

Fonte: Dados do Observatório de Educação do Grande ABC.

Os dados (Observatório de Educação do Grande ABC, 2015) evidenciam que, na região, em 2015, existiam 200 escolas, 80.275 matrículas e 7.589 professores no Ensino Fundamental na esfera municipal, e 328 instituiçóes, 13.889 professores e 195.322 estudantes matriculados na rede estadual.

Garcia et al. (2014) sinalizam que as escolas, em geral, apresentam infraestrutura apropriada e bem distinta da realidade brasileira. Os autores analisaram a realidade da regiáo, utilizando para tal a escala desenvolvida por Soares et al. (2013), e concluíram que a infraestrutura está no nível avançado (74\%). Ou seja, as escolas dessa área contam com espaços apropriados, como bibliotecas, laboratórios de ciências, quadra esportiva, entre outros, para o atendimento de alunos. Além disso, dispóem de locais especiais para atender os estudantes com de inclusão.

\section{Metodologia do estudo}

O presente estudo faz parte de um projeto maior do Observatório de Educação do Grande $\mathrm{ABC}$, que vem analisando resultados, políticas e práticas escolares dessa região. Nesta pesquisa analisa-se a questão da percepção dos alunos em relação à importância das disciplinas estudadas cotidianamente na escola. Não é investigado, nesse caso, a preferência do jovem por esta ou aquela disciplina, mas, sim, quais, na opiniáo dele, são as mais importantes no contexto escolar.

Nesse sentido, procurando conhecer a percepção do jovem sobre a importância das disciplinas, não foram incluídas no estudo, propositadamente, as matérias de Educação Física e Arte. Em estudo-piloto realizado em 2013, com 30 estudantes de três escolas da cidade de São Caetano do Sul, utilizando entrevistas, foi verificado que os alunos optavam por uma dessas duas disciplinas, comprovadamente, pelo entusiasmo e satisfação que as suas atividades proporcionavam no contexto da sala de aula ou da quadra de esportes. 
A abordagem metodológica desta pesquisa está assentada no estudo de caso, buscando descrever e explorar um cenário (YIN, 1993), coletando dados por meio da utilização de múltiplas fontes. As entrevistas realizadas, seguindo as indicações de Flick (2009), continham algumas questóes abertas e outras direcionadas e confrontativas, com o intuito de favorecer a triangulação metodológica dentro de um mesmo método e possibilitar a validação dos dados. A técnica empregada tem a finalidade de proporcionar ao aluno depoente maior liberdade nas respostas e, para o pesquisador, maior facilidade para direcionar algumas questóes e, ao mesmo tempo, comparar as respostas dos alunos entre as múltiplas perguntas realizadas.

Para realizar o estudo, foram selecionadas, inicialmente, em 2013, 30 escolas municipais de Ensino Fundamental I da região do Grande ABC Paulista (estado de São Paulo) com a utilização dos dados do Censo Escolar 2011, onde estão disponíveis informações sobre o desempenho de cada escola, município e estado do Brasil. Desses estabelecimentos de ensino, somente 17 concordaram em participar do estudo.

Dessas escolas, três pertenciam ao município de Santo André, cinco de São Bernardo, seis de São Caetano, uma de Diadema e duas de Ribeirão Pires. As escolas selecionadas foram aquelas que seus alunos possuíam nível socioeconômico médio-alto e alto (ALVES; SOARES, 2012; INEP,2013), e IDEB acima de 6,0, em 2011.

Foram escolhidas, intencionalmente, escolas com nível socioeconômico e IDEB altos, que atribuíam grande importância a tal índice. Tal fato se constituiu em uma estratégia intencional, considerando que em estudos qualitativos essa seleção proposital dos sujeitos, de eventos ou de fenômenos, é importante para a obtenção de informações relevantes, que não poderiam ser agrupadas com outro tipo de escolha. Patton (1990) denomina esse dispositivo de purposeful sampling.

Foram entrevistados, nessas escolas, 255 estudantes do $5^{\circ}$ Ano (15 de cada escola) do Ensino Fundamental I. A seleção dos estudantes de $5^{\circ}$ Ano para este estudo foi uma estratégia proposital (PATTON, 1990), considerando que eles iriam realizar a Prova Brasil naquele ano (2015). A escolha ocorreu, também, em virtude do fato de os jovens de $5^{\circ}$ e $9^{\circ}$ serem aqueles que mais participam das açóes de preparação realizadas pelas escolas e pelas redes de ensino, visando as avaliaçóes em larga escala (RONCA, 2013).

A seleção dos estudantes participantes foi realizada pelas escolas, sendo que eles pertenciam a salas de aula diferentes, mas todos de $5^{\circ}$ Ano. O fato de terem sido escolhidos pelas instituiçóes pode implicar em algum tipo interferência, já que as escolas geralmente indicam os bons alunos para participarem de algum tipo de entrevista externa. No entanto, todos os estudantes de todas as escolas 
foram selecionados da mesma forma.

Nas escolas existiam diferenças em relação à composição curricular dos $5^{\circ}$ Anos, marcadas pelas particularidades curriculares de cada município. $\mathrm{Na}$ maioria delas, havia a presença de mais de um professor generalista na mesma turma e também pelo menos um ou dois especialistas (Educação Física ou Arte ou Inglês - às vezes os três). Nesse contexto, o número de aulas de Português e Matemática era maior do que as de Ciências ou de outras disciplinas.

Nesse caso, compreendendo a questáo de os jovens serem expostos mais tempo às aulas de Português e Matemática, acrescido ao fato de que alguns professores generalistas possuíam cargas de formaçáo inicial e, sobretudo, continuada maiores nessas disciplinas, nas entrevistas foram focados os fatores que levaram o aluno a valorizar mais a disciplina. Ou seja, explorou-se as razóes dos alunos em relaçáo à importância da escolha: o aluno precisava expor os motivos de suas escolhas.

As entrevistas, com roteiro previamente estabelecido, coletavam informaçóes sobre o perfil do participante (gênero, idade, ano de estudo) e as disciplinas que eles consideravam mais importantes na escola. Essas questóes eram realizadas de forma aberta para o aluno (Quais disciplinas você valoriza mais na escola?) e sua resposta era aguardada de forma natural. Em alguns casos, a palavra valoriza tinha de ser contextualizada. O pesquisador tinha de situar: valoriza näo significa que você gosta mais, mas as matérias que você considera mais importantes na escola. Paralelamente, foram investigados os fatores que levaram o aluno a valorizar mais esta ou aquela disciplina. Nessa pergunta, questionava-se o jovem: por que você considera essas disciplinas importantes? Nesse item, o aluno precisava apontar os motivos pelos quais essas matérias eram importantes para ele.

Em algumas entrevistas foi comum a resposta do aluno: valorizo todas as disciplinas. No entanto, no desenrolar da conversa (entrevista), aos poucos, essa indicaçáo (resposta) foi sendo convertida pelo jovem em uma história mais detalhada, que incluía, na maioria das vezes, somente as disciplinas de Português e Matemática.

Dessas mesmas escolas foram entrevistados os diretores com o intuito de conhecer quais eram os planos e projetos realizados para lidar com as questóes do IDEB. Coletaram-se informaçóes sobre o perfil do participante (sexo, idade, formação, experiência) e sobre as estratégias utilizadas em relação ao IDEB. Os diretores também foram indagados se existiam estratégias para melhorar a nota da escola, quais eram e como funcionavam.

Os dados foram coletados em um período de seis meses por um grupo de pesquisadores, os quais realizaram inúmeras visitas às escolas para finalizar a coleta de dados. Os resultados foram analisados por meio da utilização da teoria 
fundamentada, no qual os dados são coletados e analisados concomitantemente. Uma abordagem que é traduzida por uma metodologia indutiva e apropriada para a construção de teorias substantivas sobre fenômenos ou eventos sociais (CORBIN; STRAUSS, 1998).

Nesse sentido, por meio de uma investigação temática, as entrevistas dos alunos e dos diretores foram todas decompostas, permitindo evidenciar os temas mais frequentes e significativos. A partir dessa codificação foi possível filtrar os dados, utilizando códigos e descritores e, ao mesmo tempo, agrupar todas as regularidades, similaridades e diferenças. Tal conversão e redução realizadas possibilitaram a construção de subcategorias, que foram analisadas no estudo.

\section{Resultados}

Este estudo mostrou a percepçáo de um grupo de alunos de escolas de Ensino Fundamental I da região do $\mathrm{ABC}$ Paulista em relação à importância das disciplinas estudadas cotidianamente na escola. Buscou revelar quais as disciplinas os estudantes mais valorizavam em um contexto escolar marcado pela valorização do IDEB.

Participaram desse estudo, 156 meninas e 99 meninos, com média de idade de aproximadamente 11 anos. Eram estudantes dos quintos anos do Ensino Fundamental I de escolas municipais. O grupo de diretores era composto de 13 mulheres e quatro homens, com idade média de 45 anos, todos formados em Pedagogia, e quase $80 \%$ deles com algum Curso de Pós-Graduação.

Os resultados mostraram que existem diferenças nas disciplinas valorizadas pelos estudantes nas escolas pesquisadas. No entanto, nas cinco cidades investigadas, em mais de $80 \%$ dos casos, as disciplinas de Português e Matemática foram as mais valorizadas pelos jovens. Em algumas cidades, como Santo André e São Caetano do Sul, em mais de 70\% dos casos, a disciplina de Ciências apareceu em terceiro lugar na valorização do aluno, mas nas outras redes de ensino, em quase $75 \%$, a mesma disciplina apareceu em quarto ou quinto lugar.

A partir dos dados analisados foi possível compreender as percepçóes dos alunos em relação às escolhas das disciplinas de Português e Matemática como as mais relevantes no contexto escolar. Tais percepçóes eram provenientes de três grandes influências: a) a influência, direta ou indireta, dos professores no dia a dia escolar; b) a influência da escola, a partir de açóes e projetos (simulados); e c) a influência rede de ensino, por meio de políticas educacionais (ex: Prova Sáo Caetano na cidade de São Caetano do Sul). 


\section{a) A influência dos professores}

Quanto à influência dos professores em relação às escolhas dos alunos, vários elementos foram citados, ocorrendo em quase $70 \%$ das escolas das cidades pesquisadas. Os estudantes mencionaram que os professores de várias disciplinas, generalistas e especialistas, solicitavam que eles estudassem as disciplinas de Português e Matemática, ou seja, se preparassem, para:

1. a realização dos simulados da escola (São Caetano do Sul, Santo André, São Bernardo);

2. o simulado da avaliação da Secretaria de Educação, na cidade em que esse sistema existia e funcionava como uma prova local (Sáo Caetano);

3. a Prova Brasil ou para o SARESP, que aconteciam no final do ano.

Essa preparação para os simulados incluía, por parte dos professores, um movimento para ensinar o aluno a responder a prova. Nesse caso, trabalhavam-se situaçóes para o aluno aprender por onde iniciar a prova, como ler as instruções e as questóes, quanto tempo se dedicar às perguntas fáceis ou difíceis, entre outras coisas. Tratava-se de um ensino de estratégias para a Prova Brasil ou para o SARESP.

Também era requisitado aos jovens que realizassem as provas utilizando raciocínio e mantendo a calma. Ou seja, solicitava-se que eles levassem a sério o teste. Em nenhuma das escolas dos municípios estudados foi encontrada uma solicitaçáo de docentes para que os alunos estudassem a disciplina de Ciências.

Uma questão relevante citada pelos alunos, encontrada em cinco escolas, foi o fato de alguns professores atribuírem notas para os alunos realizarem o exame (Prova Brasil) e fazê-lo de forma séria, ou seja, prestando atenção nas questôes da prova (ALUNO, 134). Tal fato pode ser compreendido como uma estratégia para garantir a presença dos alunos no dia da prova, sobretudo, daqueles considerados capazes intelectualmente. Ao mesmo tempo, uma açáo para que o exame fosse realizado de forma atenta pelo estudante e para aumentar a possibilidade de obter bons resultados.

\section{b) A influência da escola}

Em relação à escola, várias estratégias eram utilizadas para que os estudantes tivessem altos resultados nas avaliaçóes de larga escala. As entrevistas mostraram que quase $60 \%$ das escolas realizavam algum tipo de prova, em Português e Matemática, duas ou três vezes ao ano, simulando, por exemplo, a Prova Brasil. Tal avaliação 
tinha, segundo os entrevistados, o objetivo de preparar os alunos para a participação na Prova Brasil. Advogava-se que a realização do simulado faz com que os estudantes façam a Prova Brasil de forma mais calma e com isso eles conseguem melhores resultados, isto é certo. (DIRETOR, 12). Em nenhuma escola eram desenvolvidos simulados ou qualquer outro tipo de prova na disciplina de Ciências.

As escolas também criavam projetos de reforço escolar no contraturno para as disciplinas de Português e Matemática, e como situou um aluno: você vê porquê Matemática e Português são mais importantes, o reforço é só nelas. (ALUNO, 19). Outro aluno sinalizou que se você vai mal em História ou Geografia tem de estudar sozinho, mas em Matemática e Português não, aí você tem de vir para a escola, porque essas matérias são mais importantes do que as outras todas juntas. (ALUNO, 26).

Além do reforço escolar, exclusivo em Português e Matemática, outras atividades, tais como as de jogos, que envolviam leitura e problemas matemáticos, também eram utilizadas no contexto escolar. Tal situação visava, em algumas instituiçóes de ensino, garantir o aumento do tempo dessas disciplinas.

As escolas de São Caetano, por exemplo, tinham vários projetos de leitura para que os alunos aumentassem suas habilidades nesse quesito (ex.: Biblioteca Circulante, Oficina de Leitura, Clube de Leitores, Momento Literário). Uma escola de Santo André e uma de São Caetano utilizavam jogos de Matemática, competiçâo de raciocínio, para preparar os alunos para a Prova, incluindo os finais de semana. Não se constatou tal preocupação com a disciplina de Ciências e em quase $90 \%$ das escolas não havia nenhum tipo de reforço escolar dessa matéria, ou qualquer outro tipo de atividade para fomentar o entendimento ou o desejo de compreender mais sobre o raciocínio científico, indicando claramente o posicionamento da unidade escolar em relação à importância das disciplinas de Português e Matemática. Tal situação de organização da escola revela parte de sua identidade.

Destaca-se o fato de que alguns diretores de uma das cidades tinham estratégias bem preparadas para que os alunos, com baixo rendimento intelectual, não realizassem as provas. Eles conversavam com a família, explicando a situação de que o jovem náo tinha condiçóes de realizar o exame naquele ano e que sua participação prejudicaria a escola; alguns alunos não iam para as salas de aula onde as provas estavam sendo realizadas e, geralmente, ficavam com um funcionário em algum local (biblioteca); alguma atividade era criada, como, às vezes, outra prova, para o aluno fazer no lugar da Prova Brasil. Havia diretores, nesse município, conscientes do fato de que os alunos poderiam prejudicar a nota da escola no IDEB. Em um caso isolado, um diretor relatou que recebeu, no mês final de setembro, quatro estudantes analfabetos vindos do Nordeste brasileiro, às vésperas do exame. Nesse caso, a melhor estratégia para lidar com tal situação, segundo ele, foi conversar com os pais para que os alunos não realizassem as Prova Brasil. 


\section{c) A influência da rede de ensino}

Em relação às redes de ensino, em algumas delas, como em São Caetano, eram realizadas provas municipais para averiguação das habilidades dos alunos nas disciplinas de Português e Matemática e, nesse contexto, os recursos eram mais destinados para essas duas disciplinas.

Com objetivos variados, essas provas visavam, entre outras coisas, a preparação do jovem para a Prova Brasil, a possibilidade de compreensão do nível de ensino das escolas e a verificação do desempenho dos estudantes. Essas avaliaçóes eram realizadas para os alunos dos quintos e nonos anos e aconteciam duas ou três vezes ao longo do ano. Os resultados eram analisados pelos especialistas da Secretaria de Educação e devolvidos para as escolas que, por sua vez, analisavam o rendimento dos jovens. No entanto, em nenhuma das redes de ensino investigadas eram realizadas provas para a investigação das habilidades na disciplina de Ciências. Constatou-se, também, que duas delas não tinham um currículo definido para o desenvolvimento dessa disciplina.

Os diretores dessas escolas sinalizaram que quando recebiam os resultados das provas realizadas pelo município efetivavam reuniôes com seus professores para compreendê-los e para propor novas estratégias para aquelas classes que os alunos não obtiveram bom desempenho. Nesse contexto, os tempos de reunióes e os recursos da escola eram mais destinados aos docentes de Português e Matemática.

Os professores, por sua vez, conversavam com os estudantes sobre os resultados, os erros acontecidos e as possibilidades de melhorar nas próximas avaliaçóes. Tal situação induzia os alunos a estudar ainda mais as disciplinas de Português e Matemática, o que de fato acontecia. Na disciplina de Ciências, como disse um diretor, não havia nenhum tipo de controle de notas ou monitorização dos alunos. (DIRETOR, 13).

Alguns alunos revelaram que acabavam estudando mais as disciplinas de Português e Matemática, que eles consideravam ser as mais importantes: acabo estudando muito mais essas matérias durante a semana inteira. (ALUNO, 244). Outro jovem também sinalizou que é quase todo dia estudando essas matérias e menos as outras. Quando chega perto da prova todo professor fala para gente estudar. Às vezes o diretor vem na sala e diz para a gente estudar, que é bom para a gente e que a escola precisa de ter uma boa nota (ALUNO, 67).

Alguns diretores admitiram que a pressão era grande para se alcançar boas notas no IDESP e no IDEB. De acordo com eles há uma pressão velada da comunidade, pois os pais já conhecem esses indicadores (São Bernardo do Campo) e consultam na internet para saber a nota da escola; uma pressão da Secretaria de Educaçáo, que em alguns casos chama o diretor da escola para que explique a nota atingida; 
da mídia local, que formaliza um ranking das escolas, mostrando a posição da instituição e influenciando a opiniáo dos pais e, por fim, dos próprios professores, pois, dependendo da nota do IDEB, o bônus poderá sofrer decréscimos.

\section{Discussão dos resultados}

Os resultados mostraram um quadro que induzia os jovens a acreditar que as disciplinas mais importantes no contexto escolar eram as de Português e Matemática. Nesse cenário, esses alunos eram influenciados por açóes e atitudes de seus professores e pelas iniciativas e projetos das escolas e das redes de ensino.

Destaca-se, em primeiro lugar, desse cenário que induzia os alunos a esse imaginário (Português e Matemática sendo as disciplinas mais importantes), que os professores solicitavam abertamente que os jovens estudassem mais as disciplinas de Português e Matemática do que qualquer outra, incluindo a de Ciências. Tal situação ocorria em relação aos simulados criados pelos professores das escolas e também por outros instituídos pelas redes de ensino e organizados por especialistas das Secretarias de Educação. Como premissa central tinha-se a ideia de preparar o aluno para realização da Prova Brasil e para o Saresp.

Coutinho (2012) já havia revelado essa questão da preparação dos alunos para as provas em larga escala, utilizando para tal programas de simulados internos elaborados pelas próprias escolas e outros criados e administrados pelas redes de ensino, algumas vezes com a assessoria de empresas educacionais especializadas. Iniciativas com objetivos claros de garantir uma melhor nota nos indicadores de qualidade. Como sinalizado por Ronca (2013), tal preparação tem se tornado comum nas escolas e nas redes de ensino, ocorrendo, sobretudo nas disciplinas de Português e Matemática e nos $5^{\circ}$ e $9^{\circ}$ Anos.

Essa preparação dos alunos nas escolas incluía também a questão de ensinar estratégias para os alunos na resolução das questóes da Prova Brasil ou SARESP. Uma situação que, de acordo com Santos (2013), pode induzir ao desenvolvimento de um tipo de ensino que considera a difusão de macetes para potencializar o rendimento dos alunos. Ao mesmo tempo, esse cenário pode induzir as escolas ao deslocamento do foco do aprendizado dos alunos para um movimento de melhoria dos resultados.

Como segundo ponto, destaca-se que, além dos professores verbalizarem (às vezes pressionarem) abertamente que os alunos estudassem os simulados (da escola ou da rede de ensino), eles atribuíam notas para que eles comparecessem à prova, sobretudo os mais capacitados intelectualmente. Muitos diretores, por outro lado e de forma complementar, utilizavam estratégias deliberadas para que alguns alunos 
não realizassem o exame, sobretudo os mais incapacitados. Em ambos os casos, tais situaçóes poderão induzir à ampliação da desigualdade dentro da escola e desencadear um processo no qual investe-se deliberadamente mais nos melhores alunos, como uma estratégia mais favorável à busca por melhores resultados, do que naqueles jovens que apresentam problemas e dificuldades de aprendizagem e, nesse caso, podem comprometer o desempenho da escola nos indicadores (OLIVEIRA, 2013).

Um terceiro ponto a ser destacado relaciona-se à criação de projetos de reforço escolar exclusivo nas áreas de Português e Matemática, como se as crianças não apresentassem dificuldades de aprendizagem em outras áreas, como a de Ciências. Trata-se de um fator que induzia os alunos a acreditar que as disciplinas de PM eram as mais importantes no contexto escolar. Destaca-se também que esse tipo de projeto amplia a desigualdade na distribuição de aulas, que já ocorre entre os professores na escola, o que pode causar mal-estar entre os docentes.

Esses projetos de reforço escolar e outros de leitura ou de jogos pedagógicos matemáticos tinham como meta deliberada a questáo do aumento de tempo de exposição dos alunos aos conteúdos dessas disciplinas. Essa ampliação do tempo de formaçáo parece ser uma estratégia significativa para alcançar altos resultados na Prova Brasil e Saresp, visto que se trata de uma categoria (tempo) que influencia positivamente o desempenho dos alunos (CASTRO et al., 1984; SCHIEFELBEIN; SIMMONS, 1980).

Por fim, destaca-se a questão da pressão das Secretarias de Educação, em níveis diferentes para cada município, sobre os diretores no sentido de eles organizarem ações para a elevação dos resultados do IDEB ou do IDESP. Essa pressão pode ser um dos fatores que faz com que os diretores utilizem estratégias para impedir que alguns alunos, considerados mais fracos, realizem as provas (Prova Brasil). Uma medida utilizada por esses gestores de forma proposital para que a escola atinja melhores resultados nos indicadores e, ao mesmo tempo, uma situação que tem ocasionado maior competiçáo entre as escolas, que buscam, nesse contexto, melhores classificaçóes nos rankings.

A busca, e a obtenção, de um alto desempenho nos rankings do IDEB ou IDESP significa para a escola que será muito mais reconhecida e valorizada por sua comunidade. No entanto, afim de evitar esse simples posicionamento no ranking de posiçóes, o MEC, em 2013, com base em alguns estudos brasileiros (SOARES; ALVES, 2013), lançou o Indicador de Nível Socioeconômico das Escolas de Educação Básica (Inse) a fim de contextualizar os resultados das escolas (INEP, 2013), pois parte da aprendizagem, em países com desigualdades sociais, está relacionada ao padrão de vida das pessoas. Como resultado, será possível identificar as escolas que enfrentam elevados desafios e obtêm bons resultados no desempenho dos alunos. Além dessas questóes socioeconômicas, o MEC realizou 
e implementou um estudo-piloto, envolvendo outras disciplinas nas avaliaçóes em larga escala, incluindo a disciplina de Ciências. Isso traz esperança de que possa ser alterada, em um futuro próximo, a percepção dos estudantes e da comunidade escolar sobre a importância do ensino de Ciências.

Vale citar que essa situação de foco exclusivo nas disciplinas de Português e Matemática não é um fenômeno nacional. Em Ontário, no Canadá, tal ênfase sobre a leitura e cálculo tem afetado negativamente a qualidade do ensino de Ciências. Iniciativas orientadas para esses conteúdos e políticas de responsabilização dos professores foram destinadas para melhorar as habilidades dos alunos em leitura e cálculo, focando os testes municipais e estaduais (FAZIO; KARROW, 2014). Também, nos Estados Unidos, essa exclusividade dos exames em Matemática básica e leitura tem estreitado e restringido o currículo às disciplinas utilizadas nas avaliaçóes de larga escala, afetando a atenção com as outras disciplinas importantes, como é o caso da disciplina de Ciências (BAKER et al., 2010).

$\mathrm{O}$ que pode se depreender dos dados encontrados, a partir desse grupo de alunos brasileiros, é o fato negativo de considerarem a disciplina de Ciências como secundária e menos importante, o que poderá acarretar efeitos diretos na compreensão do jovem sobre o mundo e suas transformaçóes, dificultando também o desenvolvimento do raciocínio científico e a interpretação de fenômenos da natureza. Além disso, pode trazer consequências para o ensino de Ciências, que pode passar a ser encarado como algo desnecessário pelo estudante.

Nesse cenário de formação, o ensino de Ciência já apresenta um quadro difícil no Brasil, como observado por Tolentino Neto (2008), que mostrou o baixo interesse dos alunos de 15 anos em exercer a atividade de cientista. No entanto, esse contexto poderá se agravar ainda mais nos próximos anos, considerando a prevalência das disciplinas de Português e Matemática, decorrentes do IDEB, que tem influenciado o imaginário dos jovens brasileiros.

\section{Considerações finais}

Este estudo confirma a premissa de que a criação do IDEB, como política educacional pública, apesar de auxiliar os gestores no monitoramento da qualidade do ensino, de lutar contra o fracasso escolar, de ampliar as possibilidades de mobilização da sociedade em prol da educação e de permitir o acompanhamento das metas de ensino, trouxe como consequência, não intencional, a priorização das disciplinas de Português e Matemática, induzindo ou reforçando nos jovens o imaginário de que são mais importantes no contexto escolar do que a de Ciências ou de qualquer outra área. 
De fato, os resultados desta pesquisa mostram que os alunos de escolas de Ensino Municipal e Fundamental I, de cinco cidades do Grande ABC Paulista, valorizam muito mais as disciplinas de Português e Matemática do que a de Ciências e de outras áreas, porque, entre outras coisas, eram influenciados por atitudes e açóes de seus professores, pelas realizaçóes e projetos da escola e por iniciativas da rede de ensino, decorrentes da busca por um IDEB (ou IDESP) elevado. Uma situação que vem trazendo consequências para o ensino de Ciências, que vem sendo, nesse contexto, considerada uma disciplina secundária.

Essa situação, gerada por políticas de avaliação com foco exclusivo em Português e Matemática e de responsabilização, tem, também, ampliado a distribuição desigual dos recursos dentro das Secretarias de Educação e, o mais preocupante, dentro das próprias escolas, incluindo a questão da criação de programas, projetos educativos e pedagógicos, iniciativas e açôes, que estão muito mais centralizadas nas disciplinas de Português e Matemática.

Por fim, sinaliza-se que seria importante verificar se esses resultados aparecem em outras realidades. Outros estudos similares podem ser realizados a fim de compreender se o efeito não intencional é local, ou seja, de uma região, ou se tal situação está disseminada em todo território nacional.

\section{Referências}

ASSIS, L. M.; AMARAL, N. C. Avaliação da educação. Por um sistema nacional. Revista Retratos da Escola, Brasília, DF, v. 7, n. 12, p. 27-48, jan./jun. 2013.

ATLAS DO DESENVOLVIMENTO HUMANO. Disponível em: <http:// www.atlasbrasil.org.br/2013>. Acesso em: 13 dez. 2014.

BAKER, E. L. et al. Problems with the use of student test scores to evaluate teachers. Aug. 27, 2010. Disponível em: <http://epi.3cdn.net/ b9667271ee6c154195_t9m6iij8k.pdf>. Acesso em: 21 maio 2014.

BARBOSA, M. E. F.; FERNANDES, C. A escola brasileira faz diferença? Uma investigação dos efeitos da escola na proficiência em matemática dos alunos da $4^{a}$ série. In: FRANCO, Creso (Org.). Avaliaçáo, ciclos e promoçáo na educaçáo. Porto Alegre: Artmed, 2001. p. 121-153.

BIZZO, N. Ciências: fácil ou difícil? São Paulo: Biruta, 2009.

BRASIL, Decreto no 6.094, 24 de abril de 2007. Disponível em: <http://www. planalto.gov.br/ccivil_03/_ato2007-2010/2007/decreto/d6094.htm>. Acesso em: 7 fev. 2013. 
BRASIL. Lei de Diretrizes e Bases da Educaçáo Nacional (9.394), de 20 de dezembro de 1996. Disponível em: <http://www.presidencia.gov.br/ccivill_03/ leis/19394.htm>. Acesso em: 21 abr. 2012.

BRASIL. Constituiçáo Federal do Brasil, 1988. Presidência da República. Disponível em: http://www.planalto.gov.br/ccivil_03/constituicao/ constituicao.htm. Acesso em: 21 abr. 2013.

BRASIL. Ministério da Educação e do Desporto. Secretaria de Educação Fundamental. Parâmetros curriculares nacionais: Ensino Fundamental. Brasília, DF: MEC/SEF, $1997.10 \mathrm{v}$.

CASTRO, C. M.et al. Determinantes de la educaciónen América Latina: acceso, desempeño y equidad. ECIEL. Rio de Janeiro: Fundação Getúlio Vargas, 1984.

CORBIN, J.; STRAUSS, A. Basics of qualitative research: techniques and procedures for developing grounded theory. 2rd. ed. London: Sage Publications, 1998.

COUTINHO, M. S. Avaliação externa e currículo: possíveis impactos e implicaçóes no processo de ensino aprendizagem. In: ENDIPE - ENCONTRO NACIONAL DE DIDÁTICA E PRÁTICAS DE ENSINO, 16., 2012, Campinas. Anais... Campinas: UNICAMP, 2012.

FAZIO, X.; KARROW, D. Science takes a back seat: an unintended consequence of prioritizing literacy and numeracy achievement,2014. Disponível em: <http://www.cea-ace.ca/education-canada/article/sciencetakes-back-seat>. Acesso em: 11 jan. 2015.

FREITAS, L. C. Responsabilização, meritocracia e privatização. Conseguiremos escapar ao tecnicismo? In: SEMINÁRIO DE EDUCAÇÃO BRASILEIRA, 3., Simpósio "PNE: diretrizes para avaliação e regulação da educação nacional", Centro de Estudos Educaçáo e Sociedade (Cedes), Campinas, fev. 2011.

FLICK, U. Uma introduçáo à pesquisa qualitativa. 3. ed. Porto Alegre: Bookman, 2009.

GARCIA, P. S. Características, similaridades e diferenças entre escolas de diferentes realidades com bom desempenho acadêmico. Relatório de pósdoutorado. Faculdade de Educação da Universidade de São Paulo, 2015.

GARCIA, P. S.; ROMERO, M. C.; BASSI, M. S. A Infraestrutura das escolas de ensino Fundamental da região do Grande ABC Paulista. Revista IberoAmericana de Estudos em Educaçáo, v. 9, p. 614-631, 2014. 
GRACINDO, R. V. O gestor escolar e as demandas Instituto Brasileiro de Geografia e Estatística (IBGE), 2013. Disponível em: <http://www. cidades.ibge.gov.br/painel/populacao.php?lang=\&codmun $=354880 \&$ search $=$ sao-paulo|sao-caetano-do-sul|infograficos:-evolucao-populacional-e-piramideetaria>. Acesso em: 23 abr. 2013.

INSTITUTO NACIONAL DEESTUDOS E PESQUISAS EDUCACIONAIS - INEP (2013). Indicador de Nível Socioeconômico das Escolas de Educaçáo Básica (INSE) participantes da Avaliaçáo Nacional da Alfabetizaçáo (ANA). Disponível em: <http://download.inep.gov.br/educacao_basica/saeb/ana/ resultados/2014/nota_tecnica_inse.pdf>. Acesso em: 23 jan. 2014.

MADAUS, George; RUSSELL, Michael; HIGGINS, Jennifer. The paradoxes of high stakes testing: how they affect students, their parents, teachers, principals, schools, and society. Charlotte: Information Age, 2009.

MORTIMORE, P. The nature and findings of school effectiveness research in primary sector. In: RIDDELL, S.; PECK, E. (Org.). School effectiveness research: its message for school improvement. Londres: HMSO, 1991.

OBSERVATÓRIO DA EDUCAÇÃO DO GRANDE ABC. Relatório anual: dados técnicos. Universidade Municipal de São Caetano do Sul, 2015.

OLIVEIRA, R. P. A utilização de indicadores de qualidade na unidade escolar ou porque o IDEB é insuficiente. In: BAUER, Adriana; GATTI, Bernadete A.; TAVARES, Marialva R. (Org.). Vinte e cinco anos de avaliaçáo de sistemas educacionais no Brasil: implicaçóes nas redes de ensino, no currículo e na formação de professores. Florianópolis: Insular, 2013. p. 87-100.

PATTON, M. Q. Qualitative evaluation and research methods. 2nd ed. Newbury Park, CA: Sage, 1990.

RONCA, A. C. C. Avaliação da educação básica. Seus limites e possibilidades. Retratos da Escola, Brasília, DF, v. 7, n. 12, p. 77-86, 2013.

RUTTER, M. Fifteen thousand hours: secondary schools and their effects on children. Cambridge: Harvard University Press, 1979.

SANTOS, Lucíola L. A avaliação em debate. In: BAUER, Adriana; GATTI, Bernardete A. (Org.). Vinte e cinco anos de avaliaçáo de sistemas educacionais no Brasil: origens e pressupostos. Florianópolis: Insular, 2013. p. 229-245.

SCHIEFELBEIN, E.; SIMMONS, J. Os determinantes do desempenho escolar: uma revisão de pesquisas nos países em desenvolvimento. Cadernos de Pesquisa, São Paulo, n. 35, p. 53-72, 1980. 
TOLENTINO NETO, L. C. B. Os interesses e posturas de jovens alunos frente às Ciências: resultados do Projeto ROSE aplicado no Brasil. 2008. 172p. Tese (Doutorado em Educação) - Faculdade de Educação, Universidade de São Paulo, São Paulo, 2008.

YIN, R. K. Aplications of case study research. Thousand Oaks: SAGE Publications, 1993. 